Polymer Journa1, Vol. 4, No. 1, pp 105-110 (1973)

\title{
Studies on the Formation of Graft Copolymer by Coupling Reaction. I. Effects of the Dimension of Backbone Polymer in Solution on the Formation of Graft Copolymer
}

\author{
Koji Ishizu, Takashi Fukutomi, Toshio KakuraI, \\ and Tatsuya NoguchI \\ Tokyo Institute of Technology, 2-12, Ookayama, Meguro-ku, Tokyo, Japan.
}

(Received April 25, 1972)

\begin{abstract}
Poly(methyl methacrylate)(PMMA) was reacted with living poly $\left(\alpha^{-}\right.$ methylstyrene) at $-78^{\circ} \mathrm{C}$ in a mixture of good tetrahydrofuran and poor methylcyclohexane solvents.

The reaction conditions were chosen so as to produce graft copolymers made up of a backbone and only one branched chain (1:1-graft copolymer). Gel-permeation chromatographs(GPC), intrinsic viscosity, infrared spectra, and elemental analysis were used for the characterization of the graft copolymers.

It appears from these results that pendant side groups on a backbone molecule were not reacted with equal probability even during the first stage of this reaction, when the dimensions of the backbone molecule were small.
\end{abstract}

KEY WORDS Poly(methyl methacrylate) / Poly $(\alpha$-methylstyrene) / 1:1-Graft Copolymer / GPC / Intrinsic Viscosity / Equal Probability / Dimension /

Previously, the effects of neighbouring groups on the reaction between the pendant side groups of polymer and some reagents have been well understood. The effects on reaction probability are dominant, only at the stage where the reaction has proceeded to some extent. In another words, all pendant side groups of the polymer react with equal probability, during the first reaction stage. However in the case of reactants of high molecular weight and at rapid reaction rates, it is doubtful that they react with equal probability even at the first stage.

In the case when end and pendant side groups of the polymer react with different probabilities, the result is a graft copolymer having differing structures with differing reaction conditions.

In this paper, the authors investigated the graft copolymerization by using the reaction of living poly( $\alpha$-methylstyrene) with a PMMA backbone at $-78^{\circ} \mathrm{C}$ having THF-methylcyclohexane mixture as solvent.

The reaction conditions were chosen so as to produce a graft copolymer having a backbone and only one branched chain. The reaction probability of the pendant side groups was elu- cidated by locating the grafting point in a backbone polymer from the analysis of the graft copolymer produced.

MMA - $\alpha$-methylstyrene block copolymers were synthesized which were considered to have the same structure as block type copolymers of 1:1-graft copolymer.

The grafting point of 1:1-graft copolymer was inferred by GPC and intrinsic viscosity. This study was concerned with the effect of the dimensions of the PMMA molecule in solution on the reactivity of the pendant side groups.

\section{EXPERIMENTAL}

\section{Preparation of PMMA}

PMMA was prepared by the radical polymerization of MMA initiated by $\alpha, \alpha^{\prime}$-azobisisobutyronitrile in acetone at $60^{\circ} \mathrm{C}$ under an atmosphere of nitrogen. After the usual purification, the PMMA obtained from a 1-\% acetone solution was fractionated using methanol.

\section{Preparation of Poly( $\alpha$-methylstyryl) Anion}

$\operatorname{Poly}(\alpha$-methylstyryl $)$ anion was prepared by the polymerization of $\alpha$-methylstyrene monomer with $n$-BuLi in THF by the method of Szwarc ${ }^{1}$. 


\section{K. Ishizu, T. Fukutomi, T. KakuraI, and T. Noguchi}

Synthesis of Graft Copolymer by the Coupling Reaction with PMMA and Poly( $\alpha$-methylstyryl) Anion

The reaction was carried out under high vacuum at $-78^{\circ} \mathrm{C}$ by using sealed ampoule. Living polymer solution was dropped slowly into PMMA solution under vigorous stirring.

The concentration of living polymer was kept very low, compared to the concentration of PMMA, with the intention of forming a graft copolymer that had a backbone and only one branched chain.

Separation of Graft Copolymer and Homopolymer from the Reaction Products

The polymers obtained were then extracted by using cyclohexane and acetonitrile to separate homopoly $(\alpha$-methylstyrene) and homo-PMMA from the mixed products.

Synthesis of Block Copolymer of MMA- $\alpha-$ Methylstyrene

These block-type copolymers were considered to have the same structure as MMA $-\alpha$-methylstyrene block copolymer.

The elution peak counts of block-type copolymers for the graft copolymers produced were inferred from the GPC. The block copolymer was obtained by coupling the end group of living poly $(\alpha$-methylstyrene $)$ with 1,1-diphenylethylene. ${ }^{2}$

Fractionation of Copolymer using Sephadex LH20

After dissolving in benzene, the graft copolymers obtained were fractionated using Sephadex LH-20.

It was confirmed that the graft copolymer produced was composed of a backbone and a branched chain by comparison of the first fraction with the last by quantiative analysis of infrared spectra and elemental analysis. The model which reacted with the center-pendant group of a PMMA molecule could not be synthesized. However the last fraction was regarded as a graft copolymer formed by the coupling reaction of living polymer with MMA unit close to center of a PMMA molecule.

\section{GPC of Graft and Block Copolymer}

The elution volume is considered to be closely related to the intrinsic viscosity and molec- ular weight, and the intrinsic viscosity to the molecular structure. Thus, when two polymers have the same molecular weight and different structures, GPC is one of the most useful methods to infer the grafting point. Gel-permeation data were obtained on a Waters Model 200 GPC instrument. Measurements were made in distilled $\mathrm{THF}$ at $25^{\circ} \mathrm{C}$ with a three-column system $\left(10^{7}, 10^{6}\right.$, and $10^{5} \AA$ ) having a flow rate of $1 \mathrm{~m} l / \mathrm{min} .2 \mathrm{~m} l$ of a sample $(0.3 \mathrm{~g} / \mathrm{d} l)$ was injected for $90 \mathrm{sec}$.

\section{RESULTS AND DISCUSSION}

Synthesis of a Graft Copolymer by the Coupling Reaction between PMMA and Poly ( $\alpha$-methylstyryl) Anion

The effects of the dimensions of the PMMA molecule in solution on the reaction probability of pendant side groups were studied by varying the mixing ratio of poor solvent $(50 \mathrm{cc}$ : $9 \mathrm{cc}-$ $50 \mathrm{cc}: 3 \mathrm{cc})$. The reaction conditions for the coupling reaction between PMMA and poly$(\alpha$-methylstyryl) anion and results obtained were shown in Tables Ia and Ib.

Table I. Coupling reaction between PMMA and $\operatorname{poly}(\alpha$-methylstyryl) anion in THFmethylcyclohexane

(a)

\begin{tabular}{lcccc}
\hline No. & $\begin{array}{c}\mathrm{MCH}^{\mathrm{a}} \text { volume, } \\
\text { cc/total } \\
\text { volume, cc }\end{array}$ & $\begin{array}{c}\mathrm{PMMA}, \mathrm{b} \\
\mathrm{g}\end{array}$ & $\begin{array}{c}\text { Living } \\
\text { polymer, } \\
\mathrm{g}\end{array}$ & $\begin{array}{c}\text { Yield, } \\
\mathrm{g}\end{array}$ \\
\hline $\mathrm{R}-1$ & $9.3 / 50$ & 1.589 & 1.292 & 2.609 \\
$\mathrm{R}-2$ & $5.8 / 50$ & 1.670 & 1.292 & 2.489 \\
$\mathrm{R}-3$ & $4.0 / 50$ & 1.663 & 1.293 & 2.441 \\
\hline
\end{tabular}

a $\mathrm{MCH}$, methylcyclohexane; reaction temp, $-78^{\circ} \mathrm{C}$.

b $M_{v}, 1.20 \times 10^{5}$.

c $M_{w}, 3.00 \times 10^{5}$.

(b)

\begin{tabular}{lcccc}
\hline No. & $\begin{array}{c}\mathrm{MCH}^{\mathrm{a}} \text { volume, } \\
\text { cc/total } \\
\text { volume, cc }\end{array}$ & $\begin{array}{c}\text { PMMA, }{ }^{\mathrm{b}}{ }^{2} \text { Living } \\
\text { polymer, } \\
\mathrm{g}\end{array}$ & $\begin{array}{c}\text { Yield, } \\
\mathrm{g}\end{array}$ \\
\hline $\mathrm{R}-4$ & $5.0 / 50$ & 1.588 & 0.660 & 1.965 \\
$\mathrm{R}-5$ & $4.6 / 50$ & 1.588 & 0.623 & 1.635 \\
$\mathrm{R}-6$ & $2.7 / 50$ & 1.588 & 0.620 & 1.985 \\
\hline
\end{tabular}

${ }^{a} \mathrm{MCH}$, methylcyclohexane; reaction temp, $-78^{\circ} \mathrm{C}$.

${ }^{\mathrm{b}} M_{v}, 1.05 \times 10^{5}$.

c $M_{w}, 1.5 \times 10^{4}$. 
In Table Ia, the molecular weight $\left(M_{w}\right)$ of the living polymer was $3.00 \times 10^{5}$ and in Table Ib, $1.5 \times 10^{4}$.

In these tables, the molecular weights were calculated by using the following equations. for PMMA $[\eta]=0.71 \times 10^{-4} M_{w}{ }^{0.733}$

for $\operatorname{poly}(\alpha$-methylstyrene)

$$
[\eta]=7.81 \times 10^{-5} M_{w}{ }^{0.734}
$$

\section{Separation of Graft Copolymer and Homopolymer}

from the Reaction Products

Table II shows the results of extraction of the copolymer produced.

It may be seen from Figure 1 that the polymer extracted by acetonitrile is homo-PMMA and that by cyclohexane is homopoly $(\alpha-$ methylstyrene). Unextracted polymer(c) has absorption bands at $1730 \mathrm{~cm}^{-1}\left(\nu_{\mathrm{C}=0}\right.$ ester bond $)$ and $1600 \mathrm{~cm}^{-1}\left(\nu_{\mathrm{C}=\mathrm{C}}\right.$ aromatic ring), and was certified to be a graft copolymer.

Characterization of Block Copolymers

Table III shows molecular weight of the block copolymers obtained.

Table II. Extraction of produced copolymer

\begin{tabular}{|c|c|c|c|c|}
\hline No. & $\begin{array}{c}\text { Reaction } \\
\text { products, } \\
\quad \mathbf{g}\end{array}$ & $\begin{array}{c}\text { Extracted } \\
\text { by cyclo- } \\
\text { hexane, } \\
\mathrm{g}\end{array}$ & $\begin{array}{l}\text { Extracted } \\
\text { by aceto- } \\
\text { nitrile, } \\
\quad \mathrm{g}\end{array}$ & $\begin{array}{l}\text { Unextracted } \\
\text { polymer, } \\
\text { g }\end{array}$ \\
\hline 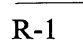 & 2.454 & 0.285 & 0.792 & 1.369 \\
\hline $\mathrm{R}-2$ & 2.337 & 0.131 & 1.082 & 1.124 \\
\hline R-3 & 2.263 & trace & 0.341 & 1.922 \\
\hline $\mathrm{R}-4$ & 1.978 & 0.121 & 0.880 & 0.977 \\
\hline R-5 & 1.659 & trace & 0.467 & 1.193 \\
\hline R-6 & 1.957 & trace & 0.855 & 1.102 \\
\hline
\end{tabular}

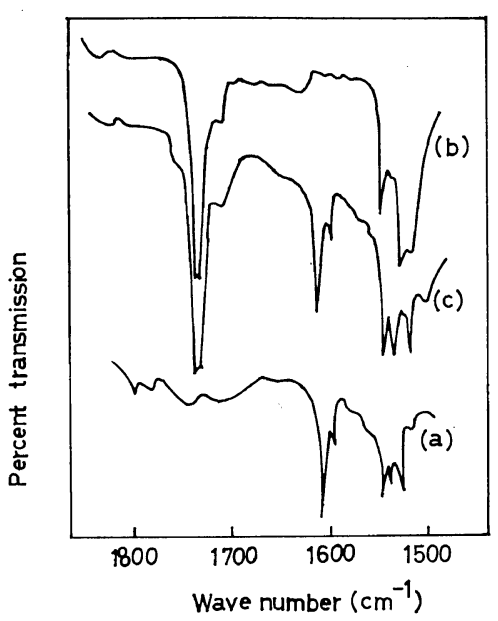

Figure 1. Infrared spectra of the polymers extracted: (a), extracted by cyclohexane; (b), extracted by acetonitrile; (c), unextracted polymer.

Using these block copolymers, the elution volume for the case where living polymer reacted with the end-pendant side group of PMMA molecule was inferred. That is to say, the values of the elution volume were plotted against the values of $\log [\eta] M$, varying $\alpha$-methylstyrene length and MMA length in three-dimensional Cartesian space (Figure 2).

GPC of Graft and Block Copolymer

Figure 3 shows the GPC of the block copolymer (cf. Table III).

Figure 4 shows the GPC of R-1-R-6.

As DP of living poly $(\alpha$-methylstyrene $)$ was increased to more than 150 , GPC showed that the graft copolymer was free of homopolymer

Table III. Summary of block copolymer

\begin{tabular}{|c|c|c|c|c|c|c|c|}
\hline \multirow[b]{2}{*}{ No. } & \multicolumn{2}{|c|}{ Molecular weight } & \multirow{2}{*}{$\begin{array}{l}\text { MMA } \\
\text { length }\end{array}$} & \multicolumn{3}{|c|}{ Intrinsic viscosity } & \multirow{2}{*}{$\begin{array}{c}\text { Count of } \\
\text { elution } \\
\text { peak }\end{array}$} \\
\hline & $\begin{array}{c}\text { Block } \\
\text { polymer }\end{array}$ & $\begin{array}{c}\alpha \text {-Methylstyrene } \\
\text { length }^{\mathrm{b}}\end{array}$ & & $\begin{array}{c}\text { Block } \\
\text { polymer }\end{array}$ & $\begin{array}{l}\alpha \text {-Methylstyrene } \\
\text { length }\end{array}$ & $\begin{array}{l}\text { MMA } \\
\text { length }\end{array}$ & \\
\hline B-1 & $3.41 \times 10^{4}$ & $3.30 \times 10^{4}$ & $1.06 \times 10^{3}$ & 0.655 & 0.156 & 0.012 & 22.0 \\
\hline B-2 & $1.04 \times 10^{5}$ & $5.41 \times 10^{4}$ & $4.97 \times 10^{4}$ & 0.940 & 0.224 & 0.190 & 21.7 \\
\hline B-3 & $3.09 \times 10^{4}$ & $6.4 \times 10^{3}$ & $2.48 \times 10^{4}$ & 0.245 & 0.047 & 0.114 & 23.2 \\
\hline B-4 & $1.61 \times 10^{4}$ & $6.4 \times 10^{3}$ & $9.68 \times 10^{3}$ & 0.335 & 0.047 & 0.057 & 23.5 \\
\hline B-5 & $1.22 \times 10^{4}$ & $6.4 \times 10^{3}$ & $5.79 \times 10^{3}$ & 0.252 & 0.047 & 0.040 & 24.0 \\
\hline B-6 & $7.13 \times 10^{5}$ & $1.67 \times 10^{5}$ & $5.46 \times 10^{5}$ & 2.00 & 0.506 & 1.100 & 18.2 \\
\hline
\end{tabular}

a By Membrane Osmometer in toluene at $37^{\circ} \mathrm{C}$.

b By intrinsic viscosity in toluene at $25^{\circ} \mathrm{C} .4$

c By relationship between molecular weight and intrinsic viscosity. ${ }^{3}$ 


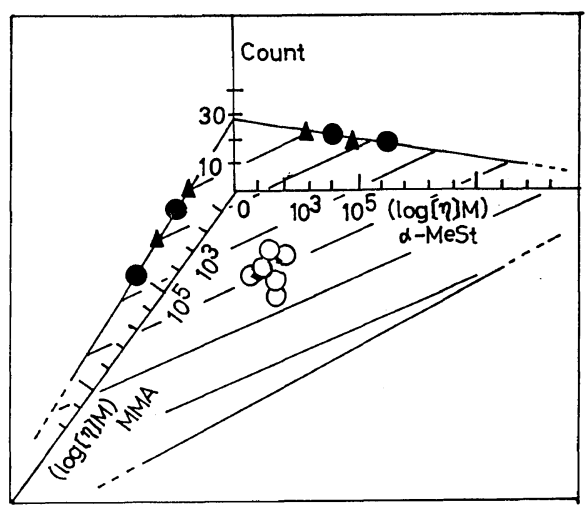

Figure 2. Plot of elution volume against $\log [\eta] M$, varying $\alpha$-methylstyrene length, and MMA length: ๑, PMMA; $\Delta, \operatorname{poly}(\alpha$-methylstyrene); $\bigcirc$, block copolymer.

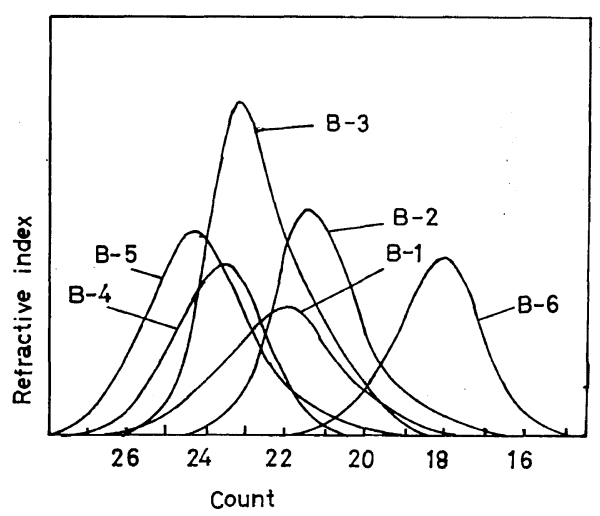

Figure 3. GPC of block copolymers.

by this method. In Figure 4, the elution peak count of block-type copolymer (dotted line) was read off from Figure 2, taking into account the molecular weight and intrinsic viscosity of the backbone polymer and the living polymer respectively. Graft copolymers reacted in mixed solvent have the same initial and final elution count.

That is to say, as expected in the previous paragraph, a copolymer having one backbone polymer and one branched chain was obtained, and the difference in elution volume might be considered to be due to the dimensions of the $1: 1$-graft copolymer produced in solution.

Finally the results of GPC in comparison with the intrinsic viscosity of each fraction of

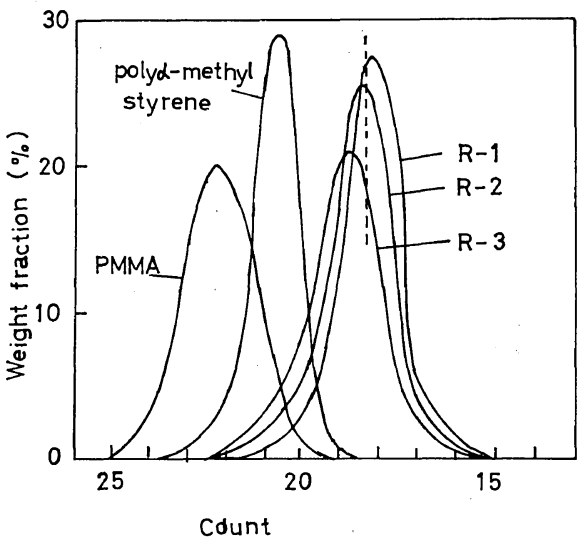

(a)

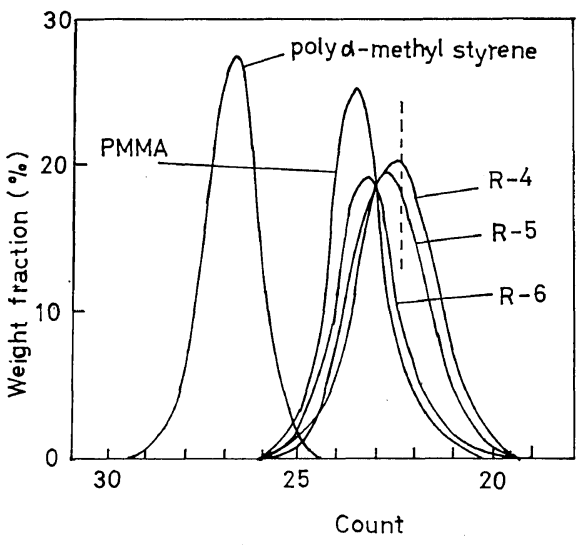

(b)

Figure 4. GPC of graft copolymer: ----, the count of elution peak for block-type copolymer.

copolymer are discussed.

Intrinsic Viscosity of Each Fraction of the Copolymer

The graft copolymers obtained were fractionated in a $1-\%$ benzene solution by Sephadex LH-20. The elution volume of each fraction was equal. Each fraction was poured into methanol and dried in vacuo. The intrinsic viscosity of the fraction was measured in toluene solution at $25^{\circ} \mathrm{C}$ by Ubbelohde viscometer. Table IV shows these results.

In order to determine the composition of the graft copolymer, the first fraction was compared with the last by elemental analysis. For example, the results of R-1 graft copolymer were as follows (Table V). 
Table IV. Intrinsic viscosity of each fraction of graft copolymer reacted in mixed solvent (in toluene at $25^{\circ} \mathrm{C}$ )

(a)

\begin{tabular}{lccc}
\hline & R-1 & R-2 & R-3 \\
\hline F-1 & 1.540 & 1.432 & 1.190 \\
F-2 & 1.320 & 1.360 & 0.987 \\
F-3 & 1.265 & 1.295 & 0.959 \\
F-4 & 1.265 & 1.295 & 0.920 \\
\hline & & Molecular & Intrinsic \\
& & weight & viscosity \\
\hline & $1.20 \times 10^{5}$ & 0.360 \\
PMMA & $3.00 \times 10^{5}$ & 0.743 \\
Living $\alpha$-methylstyrene & &
\end{tabular}

(b)

\begin{tabular}{lccc}
\hline & R-4 & R-5 & R-6 \\
\hline F-1 & 0.449 & 0.364 & 0.343 \\
F-2 & 0.441 & 0.357 & 0.323 \\
F-3 & 0.424 & 0.312 & 0.323 \\
F-4 & - & - & 0.325 \\
\hline & & Molecular & Intrinsic \\
& weignt & viscosity \\
\hline PMMA & $1.05 \times 10^{5}$ & 0.333 \\
Living $\alpha$-methylstyrene & $1.54 \times 10^{4}$ & 0.086
\end{tabular}

Table V. Elemental analysis of R-1 graft copolymer

\begin{tabular}{lcc}
\hline & \multicolumn{2}{c}{ Carbon, \% } \\
\cline { 2 - 3 } & F-1 & F-4 \\
\hline $\begin{array}{l}\text { Experimental value } \\
\text { Theoretical value }\end{array}$ & 81.18 & 80.88 \\
\hline
\end{tabular}

a This value was calculated assuming that the products were $1: 1$-graft copolymer.

It was apparent from this result that each fraction had the same composition and the same result was obtained by quantitative analysis of infrared spectra.

In spite of the fact that 1:1-graft copolymers have the same composition, the GPC of the graft copolymer and the intrinsic viscosity of each fraction showed very different characteristics (Figure 4 and Table IV). That is to say, in Figure $4 \mathrm{a}$, in the count of elution peaks the position of high molecular weight changed in the order, R-1, R-2, and R-3, where methylcyclohexane of R-1, R-2, and R-3 were introduced $9.3,5.8$, and $4.0 \mathrm{cc}$ respectively in a 50cc solution. Methylcyclohexane was the poor solvent in this reaction and the dimension of the PMMA molecule in solution for $\mathrm{R}-1$ had the smallest value.

On the other hand, the reaction probability of pendant side groups on a backbone polymer was considered on the basis of experimental results in Table IVa.

For R-1, the intrinsic viscosities of F-3 and F-4 (1.265) decreased rapidly as compared with that of F-1 (1.540).

For R-3, the intrinsic viscosity of each fraction decreased gradually in the order, F-1, F-2, F-3, and F-4.

Each fraction had the same composition, but the intrinsic viscosity of each fraction of graft copolymer produced had a different value.

It was concluded from the results described above that the graft copolymers obtained had different structures according to the variation of the reaction conditions. The dimension of the graft copolymer in solution ought to change, due to the location of the grafting point on the backbone polymer.

Generally, the intrinsic viscosity of the linear polymer is larger than that of the branched polymer, in the case of the same molecular weight. That is to say, F-1 of R-1 was considered to be the block type of copolymer, and F-4 of R-3 was considered to be the copolymer grafted on to the center-pendant groups of a PMMA molecule. In another word, as the chain dimension of PMMA in solution decreased, the living polymer reacted with the end-pendant side groups of the backbone. As the chain dimension of PMMA in solution increased, all pendant side groups began to react with equal probability. The same results for R-4, R-5 and R-6 were obtained.

The main reason is because, as the PMMA chain extended in the good solvent, living polymer could diffuse into the inside-pendant side groups of the backbone molecule. However in the poor solvent, living polymer could diffuse only to the end-pendant side group. 
K. Ishizu, T. Fukutomi, T. Kakurai, and T. Noguchi

\section{REFERENCES}

1. M. Szwarc, M. Levy, and R. Mikovitch, $J$. Amer. Chem. Soc., 78, 2656 (1956).

2. H. Ohnuma, T. Kotaka, and H. Inagaki, paper presented at SPSJ 16th Symposium on Macro- molecules, Fukuoka, 1967.

3. S. Chinai, J. Matlack, A. Resnick, and R. Samuels, J. Polym. Sci., 17, 391 (1955).

4. T. Fujimoto, N. Ozaki, and M. Nagasawa, ibid., Part A, 3, 2259 (1965). 